\title{
Morphological, anatomical characterization and profiling of laxative principles sennosides in fifteen species from genus Cassia, Chamaecrista and Senna
}

\author{
Satyanshu Kumar , Raghuraj Singh, Padamnabhi S. Nagar* and Mannu Dwivedi* \\ ICAR-Directorate of Medicinal and Aromatic Plants Research, Boriavi-387310, Anand, Gujarat, India \\ *Department of Botany, Faculty of Science, The M.S. University of Baroda, Vadodara-390002, Gujarat, India
}

\begin{tabular}{l} 
Article Info \\
\hline Article history \\
Received 12 May 2021 \\
Revised 27 June 2021 \\
Accepted 28 June 2021 \\
Published online 30 June 2021
\end{tabular}

\section{Keywords}

Cassia

Chamaecrista

Senna

Anatomy

Morphology

Sennosides

\begin{abstract}
Cassia, Chamaecrista, and Senna species are potential sources of laxative principle sennosides. About 45 species belonging to the family are reported from India. It is often essential to confirm the identity of official drug material as mentioned in the Pharmacopoeia. In the present investigation, 15 species were selected for morphological and anatomical characterization. Profiling of sennosides A and B in extracts of leaves of selected species was also carried out using a RP-HPLC method. Selected species could be differentiated on the basis of their habit, morphological and anatomical characters. S. alata, S. auriculata, S. polyphylla, S. surattensis are shrub or small tree whereas S. alexandrina, C. pumila, S. tora, C. mimosoides, C. absus, S. occidentalis, S. uniflora are herb and C. fistula, C. javanica, $C$. renigera and $S$. siamea are tree. These species can be differentiated by the shape of the leaflets, viz., oblong, obovate-oblong in S. alata, S. auriculata, C. javanica, S. surattensis, S. tora and S. uniflora; elliptic-lanceolate in S. alexandrina; ovate-elliptical in C. fistula; Ovate-lanceolate in S. occidentalis; oblong to suborbicular in Chamaecrista absus; oblong-elliptic in S. polyphylla and linear-oblong in Chamaecrista mimosoides and Chamaecrista pumila. The length of the petiole in the selected species was in the range of 0.1 to $0.9 \mathrm{~mm}$. The length of the leaves also varied in these species such as the leaflets were very small in size in $S$. auriculata, Chamaecrista mimosoides, S. polyphylla and Chamaecrista pumila. Medium size leaflets were present in S. alexandrina, C.javanica, Chamaecrista absus, C. renigera, S. tora and S. uniflora. The leaflets size were comparatively larger in S. alata, S. occidentalis, C. fistula and S. surattensis. The weight of the leaves was directly proportional to the size of the leaves. The anatomical characterstics showed that $C$. fistula, S. polyphylla, Chamaecrista pumila, S. surattensis and S. siamea had amphicribal type of vascular bundle and xylem was surrounded by phloem whereas in S. alata, S. alexandrina, Chamaecrista absus, Chamaecrista mimosoides, S. auriculata, C. javanica, C. renigera, S. tora and S. uniflora had collateral type of vascular bundle in which phloem was towards abaxial side and xylem towards adaxial side. Based on the sennoside content, three species, i.e., S. tora, C. javanica and S. occidentalis could be considered as potential alternative sources of sennoside A and B.
\end{abstract}

\section{Introduction}

Species from Senna were previously incorporated among about 600 species of Cassia (Irwin and Turner, 1960). On subsequent taxonomic classifications, this large genus was divided into three smaller genera (Cassia, Chamaecrista and Senna) and these three genera were ascribed to subtribe Cassiinae (Irwin and Barneby, 1982). However, there has been considerable diversions of opinion concerning the limitations and taxonomic status of its three constituents subgenera (Kumar et al., 2007). It is an economically as well as medicinally important genus (Mondal and Mandal, 1997). Great diversity in habit, ranging from tall trees to delicate prostrate, annual herbs may be seen within its bound (Irwin and Turner, 1960). About 45 species of Cassia are reported from India. Cassia species have been of keen interest in phytochemical and

Corresponding author: Dr. Satyanshu Kumar

Principal Scientist, ICAR-Directorate of Medicinal and Aromatic Plants Research, Boriavi-387310, Anand, Gujarat, India

E-mail: satyanshu66@gmail.com

Tel.: +91-9429667894 pharmacological research due to their excellent medicinal values. Their laxative and purgative uses are well known in folk medicine (Dalziel, 1948; Abo et al., 1999 ; Hennebelle et al., 2009). A wide range of biological activities including cytotoxic activity were reported from the different species of these genus. Anthraquinone compounds from species of genus Cassia, Chamaecrista and Senna are well established for their laxative property and also stimulating laxative activity of anthraquinone derivatives are well characterized (Sakulpanich and Gritsanapan, 2009). The laxative activity is dependent on the degree of content of total anthraquinone glycosides. Glycosides of anthraquinones are hydrolyzed by $\beta$ glucosides of the intestinal flora to free anthraquinones. Anthranones, reduced form of anthraquinones are active form of the laxative effect (Bennett, 1975 ; Bruneton 1995). It was reported that glycosides of anthraquinone have stronger activity than free aglycones (Thomson, 1971; Moreau et al., 1985; De Witte and Lemil, 1990) .

Constipation represents a major healthcare problem. About 25 per cent of the western population is affected by its acute or chronic forms. About fourteen per cent urban Indian population suffer 
from chronic constipation. The incidence of chronic constipation is more than 10 per cent worldwide. Also, 20-30\% people over the age of 60 years in the UK are reported to take laxative once a week (Mukhopadhyay et al., 1998). Constipation is a symptomatic state than a proper disease; however, it is a considerable source of inconvenience. Piles or haemorrhoids, ulcers, abdominal pain, anal fissures and fistula are some of the known medical conditions spawned by constipation. Heart attack and strokes are also common among sufferers. Sennosides are listed as one of the most important pharmaceutical preparation of the plant origin (Morinaga et al., 2000). Despite the availability of a large number of synthetic purgatives, sennosides containing prescriptions are still widely used and their importance is increasing. Food habits including low water intake have been suggested as the main factor causing constipation. However, a major concern surrounding constipation is lack of awareness about the seriousness of the disease and patients' hesitation to approach specialists for related problems. Also, home remedies is the most preferred treatment option for relief from constipation. A safer over the counter laxative plant preparations requires a better knowledge of the chemical compositions of the various utilized extracts. Different species of Cassia, Chamaecrista and Senna have been used in traditional medicines as laxative by local people for a long time.

S. alata is a shrub. Pharmacological evaluation on rat showed that S. alata had a similar laxative activity as that of senna up to $200 \mathrm{mg} /$ $\mathrm{kg}$ (leaf infusion in both cases). S. alexandrina is widely used for the relief of constipation. Sennosides are mainly present in the leaves and pods of $S$. alexandrina. It is a branching shrub with a height up to $1.80 \mathrm{~m}$. S. auriculata, commonly known as Tanners's cassia, is a common plant in Asia. It has been widely used in traditional medicines as a cure for rheumatism, conjunctivitis and diabetes (Pari and Latha, 2002). Presence of anthraquinones was reported in heartwood and pod husk of S. auriculata (Rai et al., 1997). C. absus grows as a sticky plant in almost all the states of India particularly in North-West India (Nadkarni, 1976). The plant is mainly useful in the skin diseases and eye ailments. Its seed is used as astringent and also for cathartic properties (Pandya et al., 2010). C. fistula is cultivated widely throughout India as an ornamental and deciduous plant. It is also cultivated in the tropics including West Indies, Ceylon, China, Egypt and many other countries. In Ayurvedic medicine, this plant is used for treatment of heamatemesis, pruritus, leucoderma and diabetes. Its leaf juice is given for erysipelas and skin disease (Chopra et al.,1992). Urban people of North-Eastern part of India use pods and leaves of this plant as antiallergic and also as hepatoprotective agents (Bhakta et $a l ., 2001)$. It has also been described as a cathartic agent due to anthraquinone derivatives present in the pulp of fruits (Iyengar et al., 1966). Its pods are traditionally used as a mild laxative as are the leaves and flowers but to a minor degree. It is widely used in traditional medicine as mild laxative and also as purgative for children and pregnant women (Bahorun et al., 2005; Iyengar et al., 1966). C. javanica is a medium size tree. Presence of usual and novel anthraquinones were reported from various parts of this plant (Tiwari and Singh, 1979; Chaudhari and Chawla, 1987; Singh and Singh, 1988 ; Singh et al., 1999). Seed extract of $C$. javanica exhibited purgative and haemagglutinating activity (Rastogi and Mehrotra, 1995). C. mimosoides is a low, diffuse shrub up to $1.5 \mathrm{~m}$ in height, found in open grasslands at low and medium altitudes. Its all parts were reported to contain anthraquinones. The dried young leaves and stems are used as a substitute for tea in Japan. Root is used as cure for diarrhoea (Mukherjee et al., 1987). S. occidentalis is a common weed found throughout in India. It is used in indigenous and folk medicine for a variety of purposes. $C$. occidentalis is one of the ingredients of several polyherbal formulations available in India for liver disorders (Saraf et al., 1994). S. polypylla also known as dessert senna, is a shrub or occasionally a small tree having height up to 2.00 to $3.00 \mathrm{~m}$. Chamaecrista pumila is a diffuse terrestrial and strout annual herb and usually found in shades of trees, crevices of rocks and also in the open gravelly substratum. Sennosides were reported from petroleum ether, benzene, acetone, chloroform and alcohol extracts of $C$. pumila (Sharma et al., 2012). C. renigera is a typical tropical tree and it is known as rich source of anthraquinones and flavonoids (The Wealth of India, 1992). $S$. surattensis is a flowering plant widely grown as an ornamental plants in tropical and sub-tropical areas. It has been traditionally used in many countries for food and medicinal use (Uthaya Kumar et al., 2014). S. siamea is a very widespread medicinal and food plant cultivated in Southeast Asia and sub-Saharan Africa. Its leaves and stem bark is used in constipation (Ahn et al., 1978). S. tora is a small annual legume shrub that grows as a common weed in Asian countries and cultivated as a traditional medicinal herb for multiple therapies. It is traditionally used as laxative for the treatment of leprosy and various skin disorders (Rejiya et al., 2009). S. uniflora is closely allied to $S$. obtusifolia but hairiness is the main characteristic of this species (Singh, 2001). It grows intermingled with S. tora and has the similar appearance (Meena and Yadav, 2009).

Authentication at different stages of harvesting of the plant materials as well as preparation of the final product is required in order to ensure efficacy and safety of herbal products. Misidentification of plants could be intentional or non-intentional (Kiran et al., 2010). Also, adulteration can take place because of ignorance or intentional substitution with cheaper plants which may affect efficacy and safety of the drug. Therefore, proper authentication of plant material is important. This would avoid the acceptance of wrong plant materials for drug uses. Characterization of morphological and anatomical parameters are essential for correct identification. These parameters could be used as reference for correct identification. Morphological and anatomical characterization are the general approaches for identification of medicinal plants. Literature survey revealed that information about these traits and comparative profiling of laxative principles sennosides (sennoside A, SA, $\mathrm{C}_{42} \mathrm{H}_{38} \mathrm{O}_{20}$, $\mathrm{MW}=862$ and sennoside $\left.\mathrm{B}, \mathrm{SB}, \mathrm{C}_{42} \mathrm{H}_{38} \mathrm{O}_{20}, \mathrm{MW}=862\right)$ in selected samples belonging to three genera (Cassia, Chamaecrista and Senna) is lacking (Sihanat et al., 2016). This information would be of immense utility as a number of Cassia, Chamaecrista and Senna species are widely used in many traditional systems of medicine including Ayurveda and Unani systems of medicine. The present investigation was conceived with the following objectives a. Characterization of morphological and anatomical traits of leaves of fifteen plants belonging to three genera and $b$. Comparative profiling of SA and SB in leaves extracts using a HPLC-PDA method.

\section{Materials and Methods}

\subsection{Plant material and chemicals}

The samples of S. alata, S. alexandrina, S. auriculata, Chamaecrista absus, C. fistula, C. javanica, Chamaecrista mimosoides, S. occidentalis, $S$. polyphylla, Chamaecrista pumila, C. renigera, 
S. surattensis, S. siamea, S. tora and S. uniflora were collected from Botanical Garden, Botany Department, Faculty of Science, The M.S. University of Baroda, Vadodara (latitude : $22.309^{\circ}$, longitude : $73.187^{\circ}$ and altitude : $39.00 \mathrm{~m}$ ). The collected samples of plants were confirmed with the monograph by a taxonomist and specimen of samples were deposited in herbarium. Leaves, stems and roots (where applicable) of collected samples were separated. These samples were air dried in shade at ambient temperature (25$\left.30^{\circ} \mathrm{C}\right)$, followed by hot air oven drying $\left(55-60^{\circ} \mathrm{C}\right)$ for $8-10 \mathrm{~h}$. The dried samples of leaves were made into fine powder (100 mesh) using an electric grinder. HPLC grade solvents methanol, acetonitrile and analytical grade trifluroacetic acid (TFA) were purchased from Merck, Mumbai, India. Deionized water obtained from a Millipore water purification system (Millipore, Milli Q gradient A10, France) was used throughout the experiment. Standard SA (purity $\geq 96.0 \%$ ) and SB (purity $\geq 94.5 \%$ ) were purchased from Sigma Aldrich, Mumbai, India.

\subsection{Morphological and anatomical characterization}

Leaves of 15 selected species belonging to three genera were used for morphological and anatomical characterization. The vegetative characters of the plants such as leaf length $(\mathrm{cm})$, leaf width $(\mathrm{cm})$, petiole length $(\mathrm{mm})$, fresh weight of the leaves $(\mathrm{g})$ and dry weight of the leaves $(\mathrm{g})$ were recorded for morphological characterization. For anatomical characterization, mature leaf samples were freshly collected and immediately fixed in FAA (formalin : acetic acid: alcohol $(70 \%), 10: 5: 85 \mathrm{v} / \mathrm{v} / \mathrm{v})$. After $72 \mathrm{~h}$ of fixation, samples were transferred to alcohol $(70 \%)$ for further processing and storage. Leaf samples were trimmed into 1-2 mm long pieces and dehydrated through tertiary butyl alcohol series and infiltrated in paraffin (Berlyn and Miksche, 1976; Johansen,1940). Transverse sections of leaves were directly sectioned on rotary microtome (Leica 2010R). Sections of 15-20 $\mu \mathrm{m}$ thickness were obtained in transverse planes and stained with safranin-astra blue combination (Srebotnik and Messener, 1994). After dehydration through ethanol-xylene series, sections were mounted in dibutyl phthalate xylene (DPX). Important results were microphotographed using trinocular research microscope (Leica DM 2000) attached with fire wire digital camera (Leica DFC295).

\subsection{Extracts preparation}

The powdered dried samples of leaves $(5 \mathrm{~g})$ was refluxed with 100 $\mathrm{ml}$ of aqueous alcoholic solvent (water : methanol, $20: 80$, v/v) for five hours on a water bath $\left(60^{\circ} \mathrm{C}\right)$. After that, flask was cooled at room temperature and content was filtered using vacuum filtration. Supernatant obtained was concentrated using vacuum rotary evaporator at $60^{\circ} \mathrm{C}$. Stock solution $(1 \mathrm{mg} / \mathrm{ml})$ of extract samples and standards (SA, and SB) were prepared by dissolving in aqueous alcoholic solvent (water: methanol, 2: 8, v/v). Extracts and standard samples were filtered through $0.45 \mu \mathrm{m}$ membrane filters before HPLC-PDA analysis (Dhanani et al., 2017).

\subsection{HPLC-PDA analysis}

Chromatographic analysis was carried out using a HPLC system consisting of a quaternary pump, an in-line vacuum degasser, a PDA detector (Waters 2996) and Empower software (Waters). The chromatographic separation was carried out in linear gradient elution mode on a RP-18 column ( $250 \times 4.6 \mathrm{~mm}, 5 \mu \mathrm{m}, \mathrm{x}$-Bridge, Waters) at $25^{\circ} \mathrm{C}$. The mobile phase was a mixture of TFA in water $(\mathrm{pH} 2.25$,
$0.05 \%, v / v$, solvent A) and acetonitrile (solvent B). Gradient elution mode was used for separation of SA and SB in samples. The injection volume was $20 \mu 1$. The PDA detector wavelength was set at $272 \mathrm{~nm}$ for the identification and quantification of SB and SA in different extracts of samples. Concentration of SB and SA in extract samples were calculated by the comparison of the integrated peak area of the individual compounds with those of standard curve prepared from the corresponding standards (Dhanani et al., 2017).

\section{Results}

For development of more reliable quality control methodology, correct identfication of medicinal plants is important. A conventional method for identification of plant structural is microscopic evaluation and it is a simple, rapid and inexpensive method (Sihanat et al., 2016). The taxonomy of plants in genus Cassia, Chamaecrista and Senna has several synonyms at species level and also the morphological features of many species are often similar.

\subsection{Characterization of morphological and anatomical parameters}

Morphological and anatomical characters are useful diagonostic features of the leaf for correct identification. The first objective of the present investigation was collection of natural populations of different species of Cassia, Chamaecrista and Senna for evaluating them on morphological basis. In the present study, plants with different habits were taken into consideration and included seven herbs, four shrubs and four trees (Table 1). Leaves of samples were paripinnate; leaflets among the species studied were between two to twelve pairs of various shapes (ovate, obvate, lanceolate) and texture being glabrous to pubescent (Table 1). Data collected on various morphological parameters, namely; leaf length, leaf width, petiole length, fresh and dry weight exhibited significant variations amongst the selected species (Table 2). The leaf/leaflets were dorsiventral and showed the presence of midrib and lamina. The upper epidermis was single layered composed of somewhat squarish or rectangular having thin layer of cuticle. Its outer surface possessed unicellular or uniserate and multicelluar septate trichomes. Stomata were paracytic or anomocytic or anisocytic type (Table 3, Figure 1). Palisade tissue composed of single to many layered, elongated cells, compactly or loosely arranged chloroplast with spaces or no space. Palisade layer was usually single layered with expception of Chamaecrista absus, C. renigera, C. javanica and $S$. auriculata. It was two to three layered in S. alexandrina and palisade layer was present on both the sides. Spongy parenchyma in most of the species was 4 to 5 layered with exception of 2 to 3 layer in S. alata, S. auriculata, Chamaecrista mimosoides and S. polyphylla were single to many layered loosely arranged with air cavities. The midrib was hemispherical on abaxial side and short lump on adaxial side with collenchymatous cells however Chamaecrista pumila midrib was parallel on both abaxial and adaxial side. The pericycle was parenchymatous in nature. The vascular bundle was amphicribal in C. fistula, Chamaecrista pumila, S. polyphylla, S. siamea and S. saurattensis, while, it was collateral in S. alata, S. alexandrina, S. auriculata, Chamaecrista absus, Chamaecrista mimosoides, S. occidentalis, C. javanica, C. renigera, S. tora and S. uniflora. 
Table 1: Morphological characteristics of selected species from genus Cassia, Chamaecrista and Senna

\begin{tabular}{|c|c|c|c|c|}
\hline Species & Habit & Leaf shape & No. of leaflet & Leaf surface \\
\hline Senna alata (L.) Roxb( CA) & Shrub or small tree & Oblong & $8-12$ & Sparsely pubescent or glabrous \\
\hline Senna alexandrina Mill. (CA1) & Herb or shrub & $\begin{array}{l}\text { Elliptic } \\
\text {-lanceolate }\end{array}$ & $4-6$ & Pubescent \\
\hline Senna auriculata (L.) Roxb. (CA2) & Shrub & $\begin{array}{l}\text { Oblong or } \\
\text { obovate-oblong }\end{array}$ & $6-12$ & Pubescent \\
\hline $\begin{array}{l}\text { Chamaecrista absus (L.) H. } \\
\text { (S. Irwin \& Barneby) (CA3) }\end{array}$ & Herb & $\begin{array}{l}\text { Obovate to } \\
\text { suborbicular }\end{array}$ & 2 & Pubescent \\
\hline Cassia fistula L. (CF) & Tree & Ovate-elliptic & $5-8$ & Glabrous \\
\hline Cassia javanica $\mathrm{L}$. (CJ) & Medium size tree & Oblong or oval & $6-18$ & Glabrous \\
\hline $\begin{array}{l}\text { Chamaecrista mimosoides (L.) } \\
\text { Greene (CM) }\end{array}$ & Herb & Linear-oblong & $7-60$ & Glabrous \\
\hline Senna occidentalis (L.) Link (CO) & Herbs or undershrub & $\begin{array}{l}\text { Ovate-lanceolate } \\
\text { to elliptic }\end{array}$ & $3-5$ & Sparsely pubescent or glabrous \\
\hline $\begin{array}{l}\text { Senna polyphylla (Jacq.) H.S. Irwin } \\
\text { and Barneby (CP) }\end{array}$ & Shrub & Ovate-elliptic & $5-12$ & Glabrous \\
\hline $\begin{array}{l}\text { Chamaecrista pumila (Lam.) } \\
\text { K.Larsen (CP1) }\end{array}$ & Herb & Linear-oblong & $10-18$ & Glabrous \\
\hline Cassia renigera Benth. (CR) & Tree & Oblong-elliptic & $10-20$ & Sparsely pubescent to glabrous \\
\hline $\begin{array}{l}\text { Senna surattensis (Burm.f.) } \\
\text { H.S. Irwin and Barneby (CS) }\end{array}$ & Shrub or small tree & $\begin{array}{l}\text { Elliptic or oblong } \\
\text {-obovate }\end{array}$ & $6-9$ & $\begin{array}{l}\text { Glabrous or pubescent } \\
\text { beneath }\end{array}$ \\
\hline $\begin{array}{l}\text { Senna siamea (Lam.) H.S. Irwin } \\
\text { and Barneby (CS1) }\end{array}$ & Tree & $\begin{array}{l}\text { Elliptic or oblong } \\
\text {-obovate }\end{array}$ & $8-15$ & Pubescent \\
\hline Senna tora $(\mathrm{L}$.$) Roxb (\mathrm{CT})$ & Herb & $\begin{array}{l}\text { Obovate or obovate } \\
\text {-oblong }\end{array}$ & 3 & Sparsely pubescent \\
\hline $\begin{array}{l}\text { Senna uniflora (Mill.) H.S. } \\
\text { Irwin and Barneby }(\mathrm{CU})\end{array}$ & Herb & $\begin{array}{l}\text { Obovate or obovate } \\
\text {-oblong }\end{array}$ & $3-5$ & Pubescent \\
\hline
\end{tabular}

Table 2: Variability for morphological and chemotype attributes amongst the diversified ecotypes of selected species from genus Cassia, Chamaecrista and Senna

\begin{tabular}{|c|c|c|c|c|c|c|c|c|c|c|}
\hline \multirow{2}{*}{ Name } & \multicolumn{2}{|c|}{ Length of leaves (cm) } & \multicolumn{2}{|c|}{ Width of leaves (cm) } & \multicolumn{2}{|c|}{ Fresh weight of leaves (g) } & \multicolumn{2}{|c|}{ Dry weight of leaves (g) } & \multicolumn{2}{|c|}{ Petiole (mm) } \\
\hline & Range & Mean \pm SD & Range & Mean \pm SD & Range & Mean \pm SD & Range & Mean \pm SD & Range & Mean \pm SD \\
\hline $\mathrm{CA}$ & $5.000-5.500$ & $5.267 \pm 0.252$ & $2.000-2.200$ & $2.100 \pm 0.100$ & $6.000-6.440$ & $6.187 \pm 0.227$ & $2.260-2.380$ & $2.447 \pm 0.227$ & $0.100-0.200$ & $0.167 \pm 0.058$ \\
\hline CA1 & $2.500-3.000$ & $2.733 \pm 0.252$ & $1.000-1.200$ & $1.067 \pm 0.115$ & $0.220-0.247$ & $0.235 \pm 0.014$ & $0.067-0.093$ & $0.082 \pm 0.013$ & $0.100-0.100$ & $0.100 \pm 0.000$ \\
\hline $\mathrm{CA} 2$ & $1.700-2.000$ & $1.867 \pm 0.153$ & $0.070-1.000$ & $0.387 \pm 0.531$ & $0.099-0.190$ & $0.159 \pm 0.052$ & $0.007-0.082$ & $0.032 \pm 0.043$ & $0.100-0.200$ & $0.167 \pm 0.058$ \\
\hline CA3 & $2.100-3.700$ & $2.833 \pm 0.808$ & $1.600-2.000$ & $1.800 \pm 0.200$ & $0.109-0.127$ & $0.121 \pm 0.010$ & $0.001-0.017$ & $0.006 \pm 0.009$ & $0.200-0.200$ & $0.200 \pm 0.000$ \\
\hline $\mathrm{CF}$ & $11.500-12.500$ & $11.967 \pm 0.503$ & $5.500-8.500$ & $6.967 \pm 1.501$ & $9.908-10.209$ & $10.075 \pm 0.153$ & $4.499-4.800$ & $4.666 \pm 0.153$ & $0.500-0.900$ & $0.733 \pm 0.208$ \\
\hline $\mathrm{CJ}$ & $3.200-4.400$ & $3.833 \pm 0.603$ & $1.000-1.500$ & $1.267 \pm 0.252$ & $2.390-2.450$ & $2.430 \pm 0.035$ & $0.886-0.946$ & $0.926 \pm 0.035$ & $0.100-0.200$ & $0.167 \pm 0.058$ \\
\hline $\mathrm{CM}$ & $0.900-1.200$ & $1.033 \pm 0.153$ & $0.200-0.300$ & $0.233 \pm 0.058$ & $0.055-0.051$ & $0.054 \pm 0.002$ & $0.007-0.011$ & $0.010 \pm 0.002$ & $0.100-0.100$ & $0.100 \pm 0.000$ \\
\hline $\mathrm{CO}$ & $5.000-10.000$ & $7.933 \pm 2.610$ & $1.500-4.000$ & $2.800 \pm 1.253$ & $1.167-1.186$ & $1.175 \pm 0.010$ & $0.624-0.643$ & $0.632 \pm 0.010$ & $0.200-0.300$ & $0.267 \pm 0.058$ \\
\hline $\mathrm{CP}$ & $0.600-0.700$ & $0.633 \pm 0.058$ & $0.200-0.400$ & $0.267 \pm 0.115$ & $0.103-0.126$ & $0.117 \pm 0.012$ & $0.009-0.013$ & $0.011 \pm 0.002$ & $0.100-0.100$ & $0.100 \pm 0.000$ \\
\hline CP1 & $0.050-1.000$ & $0.373 \pm 0.543$ & $0.010-0.020$ & $0.017 \pm 0.006$ & $0.175-0.188$ & $0.183 \pm 0.007$ & $0.010-0.023$ & $0.018 \pm 0.007$ & $0.100-0.100$ & $0.100 \pm 0.000$ \\
\hline $\mathrm{CR}$ & $2.800-3.100$ & $2.967 \pm 0.153$ & $2.000-2.100$ & $2.033 \pm 0.058$ & $2.300-2.380$ & $2.343 \pm 0.040$ & $0.983-1.063$ & $1.026 \pm 0.040$ & $0.100-0.200$ & $0.167 \pm 0.058$ \\
\hline $\mathrm{CS}$ & $4.000-8.000$ & $6.500 \pm 2.179$ & $2.500-3.500$ & $2.967 \pm 0.503$ & $3.250-3.290$ & $3.273 \pm 0.021$ & $0.490-0.530$ & $0.513 \pm 0.021$ & $0.200-0.200$ & $0.200 \pm 0.000$ \\
\hline CS1 & $3.500-5.500$ & $4.400 \pm 1.015$ & $1.800-2.000$ & $1.900 \pm 0.100$ & $7.200-7.280$ & $7.250 \pm 0.044$ & $2.900-2.910$ & $2.903 \pm 0.006$ & $0.400-0.500$ & $0.467 \pm 0.058$ \\
\hline СТ & $2.300-4.500$ & $3.500 \pm 1.114$ & $1.000-2.500$ & $1.833 \pm 0.764$ & $0.330-0.400$ & $0.360 \pm 0.036$ & $0.050-0.120$ & $0.080 \pm 0.036$ & $0.100-0.100$ & $0.100 \pm 0.000$ \\
\hline $\mathrm{CU}$ & $2.000-5.000$ & $3.333 \pm 1.528$ & $1.000-2.500$ & $1.867 \pm 0.777$ & $2.185-2.188$ & $2.187 \pm 0.002$ & $0.303-0.306$ & $0.305 \pm 0.002$ & $0.100-0.100$ & $0.100 \pm 0.000$ \\
\hline
\end{tabular}

$\mathrm{CA}=$ Senna alata, $\mathrm{CA} 1=$ Senna alexandrina, $\mathrm{CA} 2=$ Senna auriculata, $\mathrm{CA} 3=$ Chamaecrista absus, $\mathrm{CF}=$ Cassia fistula, $\mathrm{CJ}=$ Cassia javanica,

$\mathrm{CM}=$ Chamaecrista mimosoides, $\mathrm{CO}=$ Senna occidentalis, $\mathrm{CP}=$ Senna polyphylla, $\mathrm{CP} 1=$ Chamaecrista pumila, $\mathrm{CR}=$ Cassia renigera, $\mathrm{CS}$

$=$ Senna surattensis, $\mathrm{CS} 1=$ Senna siamea, $\mathrm{CT}=$ Senna tora, $\mathrm{CU}=$ Senna uniflora, $\mathrm{SD}=$ Standard Deviation . 
Table 3: Anatomy description of selected species from genus Cassia, Chamaecrista and Senna

\begin{tabular}{|c|c|c|c|c|c|c|c|c|}
\hline Species & Epidermis & Trichome & Stomata & $\begin{array}{l}\text { Palisade } \\
\text { tissue }\end{array}$ & $\begin{array}{l}\text { Spongy } \\
\text { tissue }\end{array}$ & Midrib & Pericycle & $\begin{array}{l}\text { Vascular } \\
\text { bundle }\end{array}$ \\
\hline $\mathrm{CA}$ & $\begin{array}{l}\text { Wavy in outline, } \\
\text { single layered, } \\
\text { rectangular shape } \\
\text { and cells with } \\
\text { cuticle and lower } \\
\text { epidermis is } \\
\text { papillose }\end{array}$ & $\begin{array}{l}\text { Posses few } \\
\text { unicellular } \\
\text { uniserate } \\
\text { multicellular } \\
\text { trichomes }\end{array}$ & $\begin{array}{l}\text { paracytic type } \\
\text { and anisocytic } \\
\text { type }\end{array}$ & $\begin{array}{l}\text { Single layered, } \\
\text { elongated cells, } \\
\text { compactly } \\
\text { arranged } \\
\text { chloroplast }\end{array}$ & $\begin{array}{l}\text { Few layered, } \\
\text { loosely } \\
\text { arranged }\end{array}$ & $\begin{array}{l}\text { Hemispherical } \\
\text { on abaxial side } \\
\text { and short lump } \\
\text { on adaxial side } \\
\text { with collench- } \\
\text { ymatous cells }\end{array}$ & $\begin{array}{l}\text { Composed } \\
\text { of parenchy- } \\
\text { matous cells }\end{array}$ & $\begin{array}{l}\text { Collateral } \\
\text { type- } \\
\text { phloem } \\
\text { towards } \\
\text { abaxial } \\
\text { side and } \\
\text { xylem } \\
\text { towards } \\
\text { adaxial } \\
\text { side }\end{array}$ \\
\hline CA1 & $\begin{array}{l}\text { Wavy in outline, } \\
\text { single layered, } \\
\text { square shape cells } \\
\text { with cuticle }\end{array}$ & $\begin{array}{l}\text { Very few } \\
\text { unicellular } \\
\text { trichomes }\end{array}$ & $\begin{array}{l}\text { paracytic type } \\
\text { and anomocytic } \\
\text { type }\end{array}$ & $\begin{array}{l}\text { Present on } \\
\text { both the side } \\
\text { of the leaves, } \\
\text { elongated, } \\
\text { loosely } \\
\text { arranged cells } \\
\text { with air spaces }\end{array}$ & $\begin{array}{l}\text { 4-5 layered } \\
\text { loosely } \\
\text { arranged } \\
\text { cells }\end{array}$ & $\begin{array}{l}\text { Hemispherical } \\
\text { on abaxial side } \\
\text { and short lump } \\
\text { on adaxial side } \\
\text { with collen- } \\
\text { chymatous } \\
\text { cells }\end{array}$ & $\begin{array}{l}\text { Composed of } \\
\text { parenchyma- } \\
\text { tous cells }\end{array}$ & $\begin{array}{l}\text { Collateral } \\
\text { type- } \\
\text { phloem } \\
\text { towards } \\
\text { side and } \\
\text { xylem } \\
\text { towards } \\
\text { abaxial } \\
\text { adaxial } \\
\text { side }\end{array}$ \\
\hline CA2 & $\begin{array}{l}\text { Wavy in outline, } \\
\text { single layered, } \\
\text { square shape cells } \\
\text { with cuticle }\end{array}$ & $\begin{array}{l}\text { Possess few } \\
\text { unicellular } \\
\text { and } \\
\text { uniserate }\end{array}$ & $\begin{array}{l}\text { paracytic type } \\
\text { and } \\
\text { anisocytic } \\
\text { type }\end{array}$ & $\begin{array}{l}\text { Double layered, } \\
\text { elongated, } \\
\text { loosely arran- } \\
\text { ged cells }\end{array}$ & $\begin{array}{l}\text { Few layered, } \\
\text { loosely } \\
\text { arranged } \\
\text { cells with } \\
\text { large spaces }\end{array}$ & $\begin{array}{l}\text { Hemispherical } \\
\text { on abaxial side } \\
\text { and short lump } \\
\text { on adaxial side } \\
\text { with collen- } \\
\text { chymatous } \\
\text { cells }\end{array}$ & $\begin{array}{l}\text { Composed of } \\
\text { parenchyma- } \\
\text { tous cells }\end{array}$ & $\begin{array}{l}\text { Collateral } \\
\text { type- } \\
\text { phloem } \\
\text { towards } \\
\text { abaxial } \\
\text { side and } \\
\text { xylem } \\
\text { towards } \\
\text { adaxial } \\
\text { side }\end{array}$ \\
\hline CA3 & $\begin{array}{l}\text { Wavy in outline, } \\
\text { single layered, } \\
\text { square shape cells } \\
\text { with cuticle }\end{array}$ & $\begin{array}{l}\text { multicellular } \\
\text { trichomes } \\
\text { Possess few } \\
\text { unicellular } \\
\text { and uniserate } \\
\text { multicellular } \\
\text { trichomes }\end{array}$ & $\begin{array}{l}\text { paracytic type } \\
\text { and anisocytic } \\
\text { type }\end{array}$ & $\begin{array}{l}\text { Single layered, } \\
\text { elongated cells, } \\
\text { compactly } \\
\text { arranged } \\
\text { chloroplast }\end{array}$ & $\begin{array}{l}\text { 4-5 layered } \\
\text { loosely } \\
\text { arranged } \\
\text { cells }\end{array}$ & $\begin{array}{l}\text { Hemispherical } \\
\text { on abaxial side } \\
\text { and short lump } \\
\text { on adaxial side } \\
\text { with collen- } \\
\text { chymatous } \\
\text { cells }\end{array}$ & $\begin{array}{l}\text { Composed of } \\
\text { parenchy- } \\
\text { matous cells }\end{array}$ & $\begin{array}{l}\text { Collateral } \\
\text { type- } \\
\text { phloem } \\
\text { towards } \\
\text { abaxial } \\
\text { side and } \\
\text { xylem } \\
\text { to wards } \\
\text { adaxial } \\
\text { side }\end{array}$ \\
\hline $\mathrm{CF}$ & $\begin{array}{l}\text { Wavy in outline, } \\
\text { single layered, } \\
\text { square shape cells } \\
\text { with cuticle }\end{array}$ & $\begin{array}{l}\text { Possess few } \\
\text { unicellular } \\
\text { trichomes }\end{array}$ & Paracytic type & $\begin{array}{l}\text { Single layer } \\
\text { present on } \\
\text { both the side } \\
\text { of the leaves, } \\
\text { elongated, } \\
\text { compactly } \\
\text { arranged cells }\end{array}$ & $\begin{array}{l}\text { 4-5 layered } \\
\text { loosely } \\
\text { arranged } \\
\text { cells }\end{array}$ & $\begin{array}{l}\text { Hemispherical } \\
\text { on abaxial side } \\
\text { and little } \\
\text { depression } \\
\text { on adaxial side } \\
\text { with collenc- } \\
\text { hymatous cells }\end{array}$ & $\begin{array}{l}\text { Composed of } \\
\text { parenchy- } \\
\text { matous cells }\end{array}$ & $\begin{array}{l}\text { Amphic- } \\
\text { ribal type- } \\
\text { xylem } \\
\text { surroun- } \\
\text { ded by } \\
\text { phloem }\end{array}$ \\
\hline CJ & $\begin{array}{l}\text { Wavy in outline, } \\
\text { single layered, } \\
\text { square shape cells } \\
\text { with cuticle }\end{array}$ & $\begin{array}{l}\text { unicellular } \\
\text { trichomes } \\
\text { throughout } \\
\text { the } \\
\text { epidermis }\end{array}$ & $\begin{array}{l}\text { anisocytic, } \\
\text { anomocytic } \\
\text { type }\end{array}$ & $\begin{array}{l}2-3 \text { layered } \\
\text { elongated } \\
\text { compactly } \\
\text { arranged cells } \\
\text { with no spaces }\end{array}$ & $\begin{array}{l}\text { single or } \\
\text { double } \\
\text { layered } \\
\text { compactly } \\
\text { arranged } \\
\text { cells }\end{array}$ & $\begin{array}{l}\text { Hemispherical } \\
\text { on abaxial side } \\
\text { and short lump } \\
\text { on adaxial side } \\
\text { with collen- } \\
\text { chymatous } \\
\text { cells }\end{array}$ & $\begin{array}{l}\text { Composed } \\
\text { of parenc- } \\
\text { hymatous } \\
\text { cells }\end{array}$ & $\begin{array}{l}\text { Collateral } \\
\text { type- } \\
\text { phloem } \\
\text { towards } \\
\text { abaxial } \\
\text { side and } \\
\text { xylem } \\
\text { towards } \\
\text { adaxial } \\
\text { side }\end{array}$ \\
\hline
\end{tabular}




\begin{tabular}{|c|c|c|c|c|c|c|c|c|}
\hline $\mathrm{CM}$ & $\begin{array}{l}\text { Wavy in outline, } \\
\text { single layered, } \\
\text { square shape cells } \\
\text { with cuticle }\end{array}$ & $\begin{array}{l}\text { Very few } \\
\text { unicellular } \\
\text { trichomes }\end{array}$ & $\begin{array}{l}\text { Paracytic and } \\
\text { anisocytic type }\end{array}$ & $\begin{array}{l}\text { Single layered, } \\
\text { elongated cells, } \\
\text { compactly } \\
\text { arranged } \\
\text { chloroplast }\end{array}$ & $\begin{array}{l}\text { 2-3 layered } \\
\text { loosely } \\
\text { arranged } \\
\text { cells }\end{array}$ & $\begin{array}{l}\text { Hemispherical } \\
\text { on abaxial side } \\
\text { and short lump } \\
\text { on adaxial side }\end{array}$ & $\begin{array}{l}\text { Composed of } \\
\text { parenchy- } \\
\text { matous cells }\end{array}$ & $\begin{array}{l}\text { Collateral } \\
\text { type- } \\
\text { phloem } \\
\text { towards } \\
\text { abaxial } \\
\text { side and } \\
\text { xylem } \\
\text { towards } \\
\text { adaxial } \\
\text { side }\end{array}$ \\
\hline $\mathrm{CO}$ & $\begin{array}{l}\text { Wavy in outline, } \\
\text { single layered, } \\
\text { square shape } \\
\text { cells with } \\
\text { cuticle }\end{array}$ & $\begin{array}{l}\text { Very few } \\
\text { unicellular } \\
\text { trichomes }\end{array}$ & $\begin{array}{l}\text { Paracytic and } \\
\text { anisocytic type }\end{array}$ & $\begin{array}{l}\text { 1-2 layered } \\
\text { elongated } \\
\text { loosely } \\
\text { arranged cells }\end{array}$ & $\begin{array}{l}4-5 \text { layered } \\
\text { loosely } \\
\text { arranged } \\
\text { chlorenchy- } \\
\text { matous cells }\end{array}$ & $\begin{array}{l}\text { Hemispherical } \\
\text { on abaxial side } \\
\text { and short lump } \\
\text { on adaxial side } \\
\text { with collen- } \\
\text { chymatous } \\
\text { cells }\end{array}$ & $\begin{array}{l}\text { Composed of } \\
\text { parenchy- } \\
\text { matous cells }\end{array}$ & $\begin{array}{l}\text { Collateral } \\
\text { type- } \\
\text { phloem } \\
\text { towards } \\
\text { abaxial } \\
\text { side and } \\
\text { xylem } \\
\text { towards } \\
\text { adaxial } \\
\text { side }\end{array}$ \\
\hline $\mathrm{CP}$ & $\begin{array}{l}\text { Wavy in outline, } \\
\text { single layered, } \\
\text { square shape cells } \\
\text { with cuticle }\end{array}$ & $\begin{array}{l}\text { Possess few } \\
\text { unicellular } \\
\text { trichomes }\end{array}$ & Paracytic type & $\begin{array}{l}\text { Single layered, } \\
\text { elongated cells, } \\
\text { compactly } \\
\text { arranged } \\
\text { chloroplast }\end{array}$ & $\begin{array}{l}\text { 2-3 layered } \\
\text { compactly } \\
\text { arranged } \\
\text { with no } \\
\text { spaces }\end{array}$ & $\begin{array}{l}\text { Hemispherical } \\
\text { on abaxial side } \\
\text { and little } \\
\text { depression on } \\
\text { adaxial side } \\
\text { with collenc- } \\
\text { hymatous cells }\end{array}$ & $\begin{array}{l}\text { Composed } \\
\text { of parenchy- } \\
\text { matous cells }\end{array}$ & $\begin{array}{l}\text { Amphicri } \\
\text { bal type- } \\
\text { xylem } \\
\text { surroun- } \\
\text { ded by } \\
\text { phloem }\end{array}$ \\
\hline CP 1 & $\begin{array}{l}\text { Wavy in outline, } \\
\text { single layered, } \\
\text { square shape cells } \\
\text { with cuticle }\end{array}$ & $\begin{array}{l}\text { Very few } \\
\text { unicellular } \\
\text { trichomes }\end{array}$ & $\begin{array}{l}\text { anisocytic, } \\
\text { anomocytic } \\
\text { type }\end{array}$ & $\begin{array}{l}\text { Single layered } \\
\text { elongated } \\
\text { loosely } \\
\text { arranged cells }\end{array}$ & $\begin{array}{l}3-4 \text { layered } \\
\text { loosely } \\
\text { arranged } \\
\text { cells }\end{array}$ & $\begin{array}{l}\text { Parallel on } \\
\text { both abaxial } \\
\text { and adaxial } \\
\text { side }\end{array}$ & $\begin{array}{l}\text { Composed } \\
\text { of parenchy- } \\
\text { matous cells }\end{array}$ & $\begin{array}{l}\text { Amphicri } \\
\text { bal type- } \\
\text { xylem } \\
\text { surroun- } \\
\text { ded by } \\
\text { phloem }\end{array}$ \\
\hline CR & $\begin{array}{l}\text { Wavy in outline, } \\
\text { single layered, } \\
\text { square shape cells } \\
\text { with cuticle }\end{array}$ & $\begin{array}{l}\text { Possess few } \\
\text { unicellular } \\
\text { and uniserate } \\
\text { multicellular } \\
\text { trichomes }\end{array}$ & $\begin{array}{l}\text { anisocytic, } \\
\text { anomocytic } \\
\text { type }\end{array}$ & $\begin{array}{l}\text { 1-2 layered } \\
\text { elongated } \\
\text { compactly } \\
\text { arranged cells } \\
\text { with no spaces }\end{array}$ & $\begin{array}{l}\text { 3-4 layered } \\
\text { loosely } \\
\text { arranged } \\
\text { cells }\end{array}$ & $\begin{array}{l}\text { Hemispherical } \\
\text { on abaxial side } \\
\text { and little } \\
\text { depression } \\
\text { on adaxial side } \\
\text { with collenc- } \\
\text { hymatous cells }\end{array}$ & $\begin{array}{l}\text { Composed } \\
\text { of parench- } \\
\text { ymatous cells }\end{array}$ & $\begin{array}{l}\text { Collateral } \\
\text { type- } \\
\text { phloem } \\
\text { towards } \\
\text { abaxial } \\
\text { side and } \\
\text { xylem } \\
\text { towards } \\
\text { adaxial } \\
\text { side }\end{array}$ \\
\hline CS & $\begin{array}{l}\text { Wavy in outline, } \\
\text { single layered, } \\
\text { square shape cells } \\
\text { with cuticle }\end{array}$ & $\begin{array}{l}\text { Possess no } \\
\text { trichomes }\end{array}$ & paracytic type & $\begin{array}{l}\text { Single layered } \\
\text { elongated loo- } \\
\text { sely arranged } \\
\text { cells with } \\
\text { large air } \\
\text { spaces }\end{array}$ & $\begin{array}{l}\text { 3-4 layered } \\
\text { loosely } \\
\text { arranged } \\
\text { cells } \\
\text { with large } \\
\text { air spaces }\end{array}$ & $\begin{array}{l}\text { Hemispherical } \\
\text { on abaxial side } \\
\text { and little } \\
\text { depression } \\
\text { on adaxial side } \\
\text { with collench- } \\
\text { ymatous cells }\end{array}$ & $\begin{array}{l}\text { Composed } \\
\text { of parench- } \\
\text { ymatous cells }\end{array}$ & $\begin{array}{l}\text { Amphicri } \\
\text { bal type- } \\
\text { xylem } \\
\text { surroun- } \\
\text { ded by } \\
\text { phloem }\end{array}$ \\
\hline CS1 & $\begin{array}{l}\text { Wavy in outline, } \\
\text { single layered, } \\
\text { square shape cells } \\
\text { with cuticle }\end{array}$ & $\begin{array}{l}\text { Possess few } \\
\text { unicellular } \\
\text { and uniserate } \\
\text { multicellular } \\
\text { trichomes }\end{array}$ & paracytic type & $\begin{array}{l}\text { Single layer } \\
\text { present on } \\
\text { both the side } \\
\text { elongated, } \\
\text { compactly } \\
\text { arranged cells }\end{array}$ & $\begin{array}{l}4-5 \text { layered } \\
\text { loosely } \\
\text { arranged } \\
\text { cells }\end{array}$ & $\begin{array}{l}\text { Hemispherical } \\
\text { on abaxial side } \\
\text { and little } \\
\text { depression } \\
\text { on adaxial side } \\
\text { with collench- } \\
\text { ymatous cells }\end{array}$ & $\begin{array}{l}\text { Composed } \\
\text { of parench- } \\
\text { ymatous cells }\end{array}$ & $\begin{array}{l}\text { Amphicri } \\
\text { bal type- } \\
\text { xylem } \\
\text { surroun- } \\
\text { ded by } \\
\text { phloem }\end{array}$ \\
\hline
\end{tabular}




\begin{tabular}{|l|l|l|l|l|l|l|l|l|}
\hline CT & $\begin{array}{l}\text { Wavy in outline, } \\
\text { single layed, } \\
\text { square shape cells } \\
\text { with cuticle } \\
\text { unicellular } \\
\text { and uniserate } \\
\text { multicellular } \\
\text { trichomes } \\
\text { anisocytic } \\
\text { type }\end{array}$ & $\begin{array}{l}\text { paracytic type } \\
\text { loosely } \\
\text { arranged } \\
\text { cells }\end{array}$ & $\begin{array}{l}\text { 4-5 layered } \\
\text { loosely } \\
\text { arranged } \\
\text { cells }\end{array}$ & $\begin{array}{l}\text { Hemispherical } \\
\text { on abaxial side } \\
\text { and short lump } \\
\text { on adaxial side } \\
\text { with colenc- } \\
\text { ymatous cells }\end{array}$ & $\begin{array}{l}\text { Composed } \\
\text { of parench- } \\
\text { ymatous cells }\end{array}$ & $\begin{array}{l}\text { Collateral } \\
\text { type- } \\
\text { phloem } \\
\text { towards } \\
\text { abaxial } \\
\text { side and } \\
\text { xylem } \\
\text { towards } \\
\text { adaxial } \\
\text { side }\end{array}$ \\
\hline CU & $\begin{array}{l}\text { Wavy in outline, } \\
\text { single layered, } \\
\text { square shape cells } \\
\text { with cuticle }\end{array}$ & $\begin{array}{l}\text { Possess few } \\
\text { unicellular } \\
\text { and uniserate } \\
\text { multicellular } \\
\text { trichomes }\end{array}$ & $\begin{array}{l}\text { anisocytic, } \\
\text { anomocytic } \\
\text { type }\end{array}$ & $\begin{array}{l}\text { Single layered } \\
\text { very elonga- } \\
\text { ted loosely } \\
\text { arranged } \\
\text { cells }\end{array}$ & $\begin{array}{l}\text { 4-5 layered } \\
\text { loosely } \\
\text { arranged } \\
\text { cells }\end{array}$ & $\begin{array}{l}\text { Hemispherical } \\
\text { on abaxial side } \\
\text { and little } \\
\text { depression on } \\
\text { adaxial side } \\
\text { with collenchy } \\
\text { matous cells }\end{array}$ & $\begin{array}{l}\text { Composed } \\
\text { parenchy- } \\
\text { matous cells }\end{array}$ & $\begin{array}{l}\text { Collateral } \\
\text { type- } \\
\text { phloem } \\
\text { towards } \\
\text { abaxial } \\
\text { side and } \\
\text { xylem } \\
\text { towards } \\
\text { adaxial } \\
\text { side }\end{array}$ \\
\hline
\end{tabular}

$\mathrm{CA}=$ Senna alata, $\mathrm{CA} 1=$ Senna alexandrina, $\mathrm{CA} 2=$ Senna auriculata, $\mathrm{CA} 3=$ Chamaecrista absus, $\mathrm{CF}=$ Cassia fistula, $\mathrm{CJ}=$ Cassia javanica, $\mathrm{CM}=$ Chamaecrista mimosoides, $\mathrm{CO}=$ Senna occidentalis, $\mathrm{CP}=$ Senna polyphylla, $\mathrm{CP} 1=$ Chamaecrista pumila, $\mathrm{CR}=$ Cassia renigera, $\mathrm{CS}$ $=$ Senna surattensis, $\mathrm{CS} 1=$ Senna siamea, $\mathrm{CT}=$ Senna tora, $\mathrm{CU}=$ Senna uniflora .

Table 4: Extract yield and sennosides (SB and SA) content in extracts of selected species from genus Cassia, Chamaecrista and Senna

\begin{tabular}{|l|c|l|l|l|}
\hline Species & Extract yield $(\boldsymbol{\%})$ & SB $(\boldsymbol{\%})$ & SA $(\%)$ & Total (SB + SA, \%) \\
\hline CA & 38.05 & 0.1900 & 0.2050 & 0.3950 \\
\hline CA1 & 30.09 & 0.7100 & 0.4560 & 1.1660 \\
\hline CA2 & 29.79 & 0.2946 & 0.0993 & 0.3939 \\
\hline CA3 & 30.49 & nd & nd & - \\
\hline CF & 23.62 & 0.1700 & 0.2050 & 0.3750 \\
\hline CJ & 36.99 & 0.6272 & 0.0124 & 0.6396 \\
\hline CM & 19.68 & nd & nd & - \\
\hline CO & 30.73 & 0.4623 & 0.1499 & 0.6122 \\
\hline CP & 19.92 & nd & nd & - \\
\hline CP1 & 44.44 & nd & nd & - \\
\hline CR & 30.80 & nd & nd & - \\
\hline CS & 56.20 & 0.000445 & 0.000187 & 0.000632 \\
\hline CS1 & 25.42 & nd & nd & - \\
\hline CT & 11.56 & 0.6312 & 0.0364 & 0.6676 \\
\hline CU & 31.12 & nd & nd & - \\
\hline
\end{tabular}

$\mathrm{CA}=$ Senna alata, $\mathrm{CA} 1=$ Senna alexandrina, $\mathrm{CA} 2=$ Senna auriculata, $\mathrm{CA} 3=$ Chamaecrista absus, $\mathrm{CF}=$ Cassia fistula, $\mathrm{CJ}=$ Cassia javanica, $\mathrm{CM}=$ Chamaecrista mimosoides, $\mathrm{CO}=$ Senna occidentalis, $\mathrm{CP}=$ Senna polyphylla, $\mathrm{CP} 1=$ Chamaecrista pumila, $\mathrm{CR}=$ Cassia renigera, $\mathrm{CS}=$ Senna surattensis, $\mathrm{CS} 1=$ Senna siamea, $\mathrm{CT}=$ Senna tora, $\mathrm{CU}=$ Senna uniflora, $\mathrm{nd}=\mathrm{Not}$ detected.

\subsection{Profiling of sennosides A and B in leaves extracts}

Most of phytochemical work on different species of Cassia, Chamaecrista and Senna species are restricted to isolation, characterization and evaluation of biological activities. Senna extracts are complex mixture with several active constituents such as dianthrone glycosides (sennosides A, B, C and D), free anthraquinone (aloe-emodin, chrysophenol, rhein) and anthraquinone glycosides. Among these constituents, sennoside A and $\mathrm{B}$ are present in higher concentration than the other constituents.
Senna extracts are widely used in the treatment of intestinal constipation and their strong laxative effects are attributed to sennosides A and B. In addition to that, tissue containing sennosides are efficient sources of health teas (Kojima et al., 2001). Sennosides $\mathrm{A}$ and $\mathrm{B}$ (Figure 2) are unique anthraquinones having double carboxylic acid-, hydroxyl-, carbonyl-and O-glucosyl-groups at the C-3, C-1,C-9 and C-8 possible and possessing threo- and erythroconfigurations between $\mathrm{C}-10$ and $\mathrm{C}-10$, respectively (Putalun $e t$ al., 2004). 
In the present investigation $\mathrm{SB}$ and $\mathrm{SA}$ were identified and quantified in 15 species. Sennosides A and B were identified and quantified only in S. alexandrina (CA1), S. tora (CT), C. javanica (CJ), S. occidentalis (CO), S. alata (CA), S. auriculata (CA2), C. fistula (CF), S. surattensis (CS) (Table 4, Figure 3). $\mathrm{SB}$ and SA were not detected in species namely Chamaecrista absus (CA3), Chamaecrista mimosoides (CM), Senna polyphylla (CP), Chamaecrista pumila (CP1), Cassia renigera (CR), Senna siamea (CS1) and Senna uniflora
(CU). The content of $\mathrm{SB}$ varied in the following order: $\mathrm{CA} 1>$ $\mathrm{CT}>\mathrm{CJ}>\mathrm{CO}>\mathrm{CA} 2>\mathrm{CA}>\mathrm{CF}>\mathrm{CS}$. Similarly, SA content was maximum in CA1 followed by $\mathrm{CF}$ and $\mathrm{CA}, \mathrm{CO}, \mathrm{CA} 2, \mathrm{CT}$, $\mathrm{CJ}$, CS. The total sennoside $(\mathrm{SB}+\mathrm{SA})$ varied in the following order : $\mathrm{CA} 1>\mathrm{CT}>\mathrm{CJ}>\mathrm{CO}>\mathrm{CA}>\mathrm{CA} 2>\mathrm{CF}>\mathrm{CS}$. Based on the sennoside content, it could be possible to select alternative source of laxative drug as the total anthraquninone content should not be less than $0.5 \%$ of dried leaf raw materials (Sakulpanich and Gritsanapan, 2009).

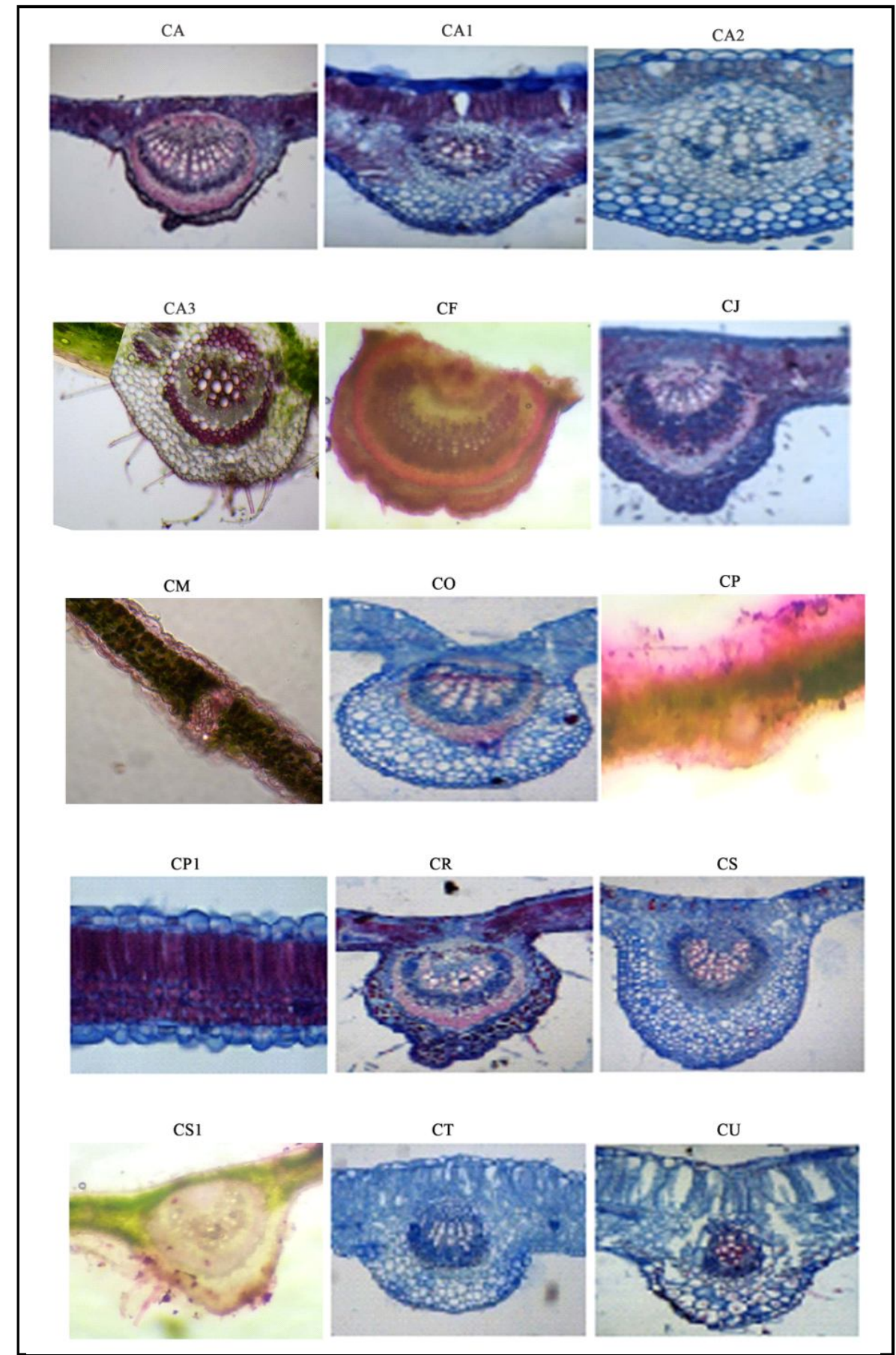

Figure 1: Anatomical characteristic of selected species from genus Cassia, Chamaecrista and Senna. 
<smiles></smiles>

Sennoside A (1) 10-10' threo

Sennoside B (2) 10-10' erythro

Figure 2: Chemical structure of sennosides A and B.

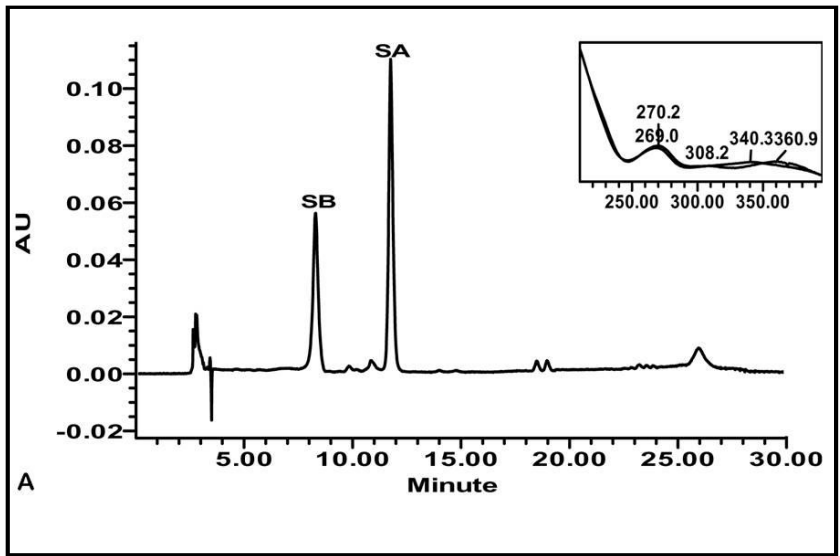

(A) Mixtute of Standard SB and SA

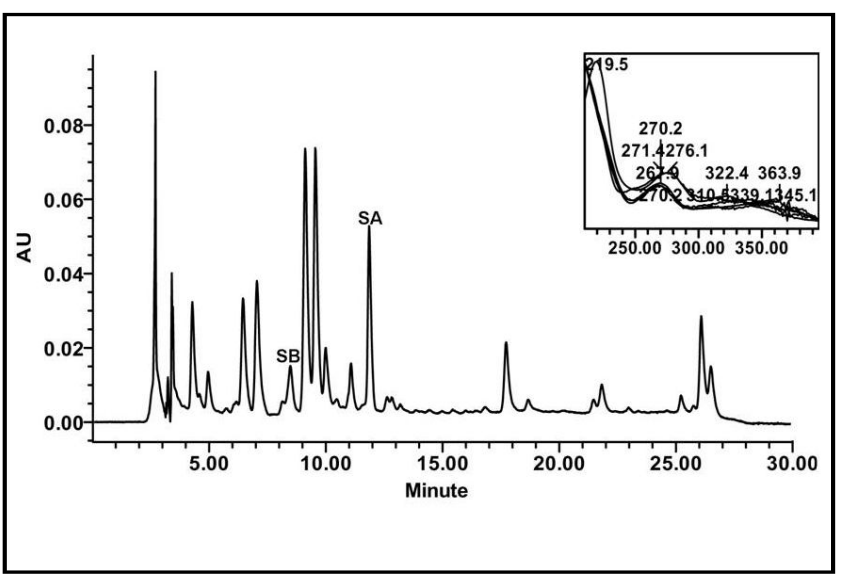

(B) S. alexandrina

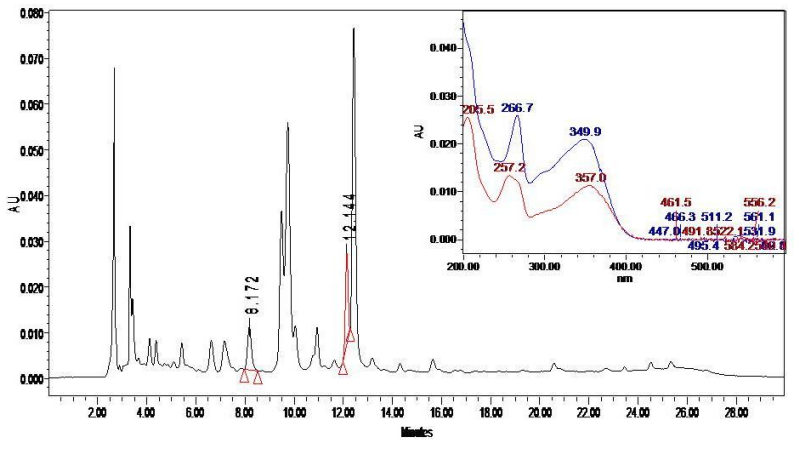

(C) S. tora

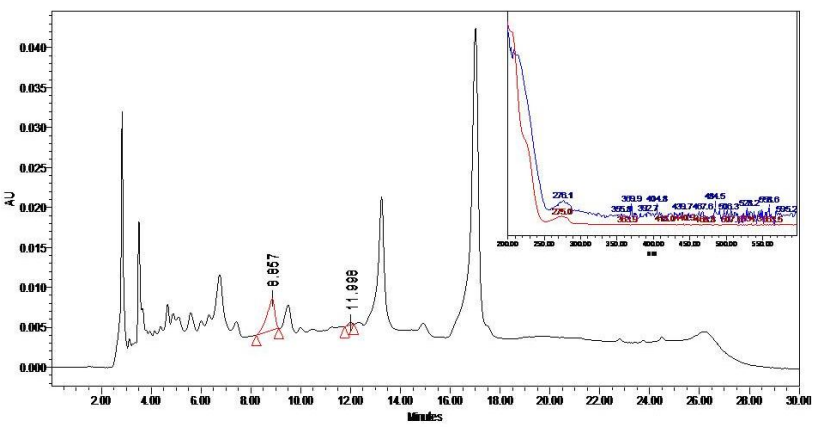

(D) S. javanica

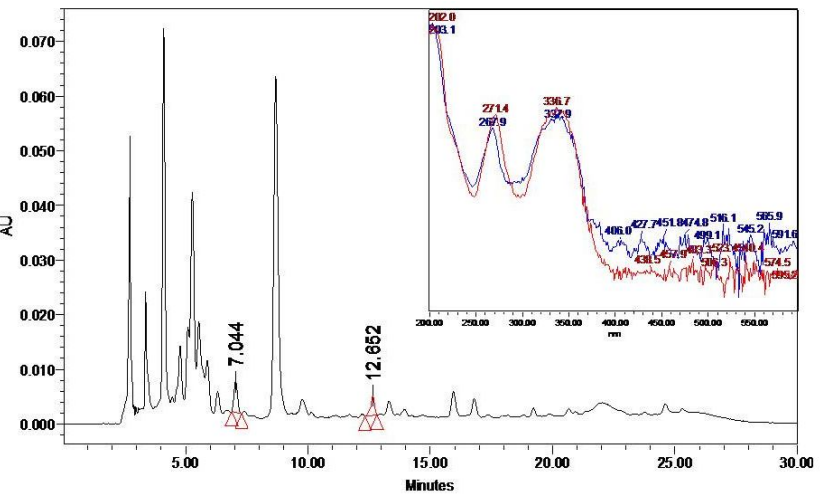

(E) S. occidentalis

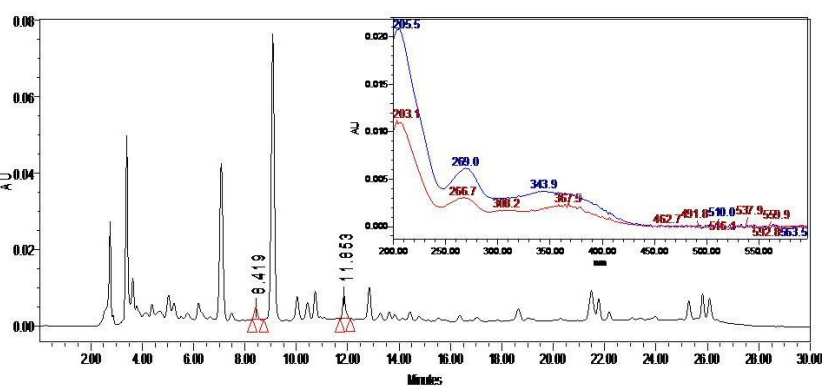

(F) S. alata 


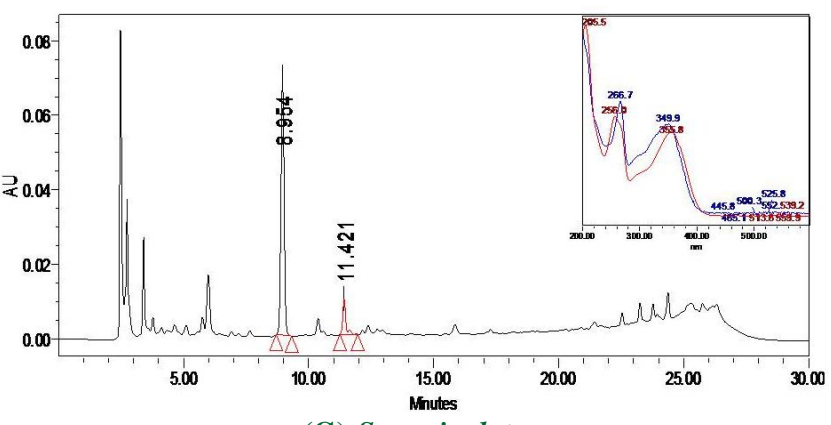

(G) S. auriculata

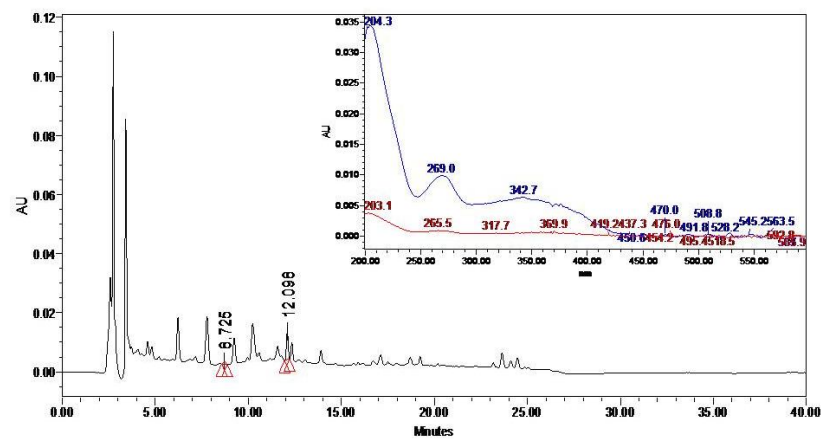

(H) C. fistula

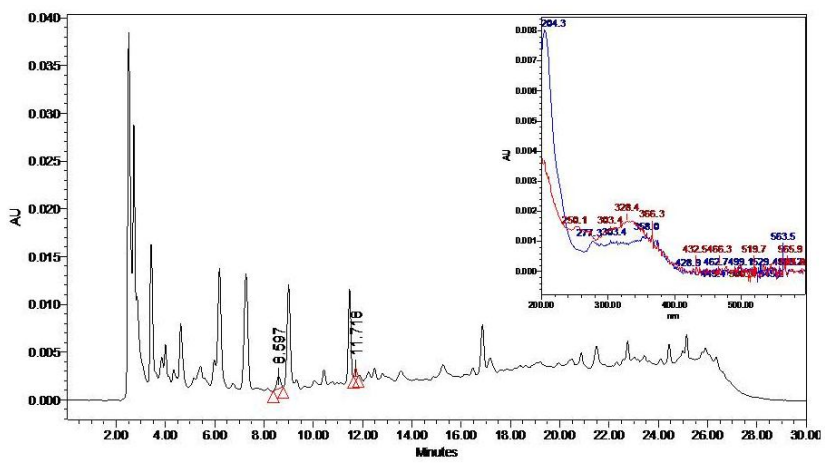

(I). S. surattensis

Figure 3: HPLC-PDA chromatogram: (A).Mixture of standard of SB and SA, (B) S. alexandrina, (C) S. tora, (D) S. javanica, (E) S. occidentalis, (F) S. alata, (G) $S$. auriculata, (H) C. fistula, (I) S. surattensis.

\section{Discussion}

Earlier, Sihanat et al. (2016) reported characteristics and number of trichome of leaves, from sixteen species of Cassia found in Thailand. The trichome characteristics of investigated Cassia spp. were uniseriate, uni-or multicellular non-glandular and multicellular grandular types. However, trichome in some Cassia spp. were absent. C. javanica L. had the highest trichome number in both dorsal $(78.94 \pm 2.86)$ and ventral $(127.39 \pm 2.46)$ surfaces of the leaf whereas $C$. surattensis Burm.f had the lowest trichome numbers only on ventral $(3.46 \pm 0.80)$ surface. Based on the presence of trichomes on leaf surface, Cassia spp. were classified into three major groups. The trichome was present on both dorsal and ventral surfaces in 10 species $(C$. bakeriana, $C$. fistula, $C$. grandis, $C$. javanica, C. alata, C. angustifolia, C. siamea, C. spectabilis, C. timoriensis and $C$. hirsuta). In other three species, namely; $C$. sulfurea, $C$. surrattensis and $C$. tora, trichome was present on ventral surfaces. Trichome was absent in rest three species $(C$. garrenttiana, C. occidentalis and C. sophera).

Khan et al. (2011) reported that cluster analysis exhibited genetic diversity among four species of Senna. These four species were clustered into two groups: first group comprised of S. aungustifolia, which had high similarity $(72.73 \%)$ to each other as compared to the second group which had $S$. sophera and $S$. tora. The authors also reported that the $S$. aunguistifolia and S. acutifolia had morphological similarities in leaves to great extent and in dried state, it was very difficult to differentiate to each other. However, in RAPD analysis both species showed more genetic divergence. These two species are so closely related that their status has been variously interpreted. The results demonstrated the ability of RAPD markers to reliably differentiate between $S$. surattensis and $S$. sulfurea.

Morinaga et al. (2009) reported SB and SA in leaves of nine Cassia species using eastern blotting technique with anti-sennoside $\mathrm{A}$ and anti-sennoside B monoclonal antibodies. The total sennoside $(\mathrm{SB}+\mathrm{SA}, \mu \mathrm{g} / \mathrm{mg}$ dry wt powder) varied in the following order : $C$. angustifolia $>$ C. alata $>$ C. fistula $>$ C. bakeriana $>$ C. mimosoides $>$ C. siamea $>$ C. floribunda $>$ C. tora $>$ C. surattensis. Lohar et al. (1975) reported phytochemical studies on seven Cassia species of India namely $C$. angustifolia, C. fistula, $C$. javanica, $C$. siamea, $C$. tora, $C$. sophera and $C$. auriculata collected from Western Rajasthan, India. Total sennosides content in the leaves were estimated using spectrophotometric method as reported in British Pharmacopoeia (Anonymous, 1968). Total sennoside (\%) was highest in $C$. angustifolia followed by $C$. fistula. The following order was observed for total sennosides content: $C$. angustifolia $(4.23)>C$. fistula $(1.80)>C$. javanica $(0.20)>C$. auriculata $(0.15)>C$. tora $(0.14)>C$. siamea $(0.07)>C$. sophera $(0.07)$. Earlier, the sennoside contents in the leaves and seeds of wild $C$. angustifolia were reported to be 3.0-5.0 and 2.4-3.0\%, respectively (Stoll et al., 1949; Pendse et al. 1973).

Asseleih et al. (1990) reported seasonal variation in the content of sennosides in leaves and pods of two $C$. fistula populations. The highest sennoside contents detected in C. fistula were $1.00-1.50 \%$ in leaves and $1.00-1.90 \%$ in pods as compared to senna species in which sennosides contents (\%) were reported to be in the range of 2.00-3.00 in leaves and 2.50-4.50 in pods of C. acuitifolia and 2.003.00 in leaves and 1.20-2.50 in pods of $C$. anguistifolia. Elujoba $e t$ al.(1989) reported combined anthraquinone content and laxative properties of leaves of 10 Cassia species cultivated in Nigeria with C. acuitifolia as the reference standard. The results of both chemical and biological experiments suggested that $C$. alata and C. podocarpa were the most likely candidates for drug development.

\section{Conclusion}

Although, the quantitative method for the chemical markers confirm the presence of compounds, it does not confirm the presence of plant material which contains the chemical markers. Wide diversity was recorded for the studied morphological and anatomical characteritcics among the selected species. Based on the sennoside content, three species, namely; S. tora, C. javanica and S. occidentalis could be considered as potential alternative sources of sennosides A and B for laxative drug. 


\section{Acknowledgments}

The authors (SK and RS) express sincere thanks to Indian Council of Agricultural Research (ICAR) for funding the present investigation in the form of a research project "ICAR-Network Project on High Value Compounds/Phytochemicals". One of authors (SK) acknowledges the DST-SERB, New Delhi for International Travel Support grant of SERB, DST, New Delhi for attending the $3^{\text {rd }}$ International Conference on Natural Products utilization: from Plants to Pharmacy Shelf held in Bulgaria.

\section{Conflicts of interest}

The authors declare that there are no conflicts of interest relevant to this article.

\section{References}

Abo, K.A.; Lasaki, S.W. and Adeyemi, A.A. (1999). Laxative and antimicrobial properties of Cassia species growing in Ibadan. Nigerian J. Nat. Prod. and Med., 8:47-50. doi:10.4314/njnpm.v3i1.11758.

Ahn, B.Z; Degen, U.; Lienjayetz, C.; Pachaly, P. and Zymalkowski, F. (1978) Constituents of Cassia siamea. Arch. Pharm., 311:569-578. doi: 10.1002 /ardp.19783110703.

Anonymous (1968). British pharmaceutical codex. Pharmaceutical Press, London.

Asseleih, L.M.C.; Hernandez, O.H., and Sanchez, J.R. (1990). Seasona variations in the content of sennosides in leaves and pods of two Cassia fistula populations. Phytochemistry, 29:3095-3099.doi.org/ 10.1016/0031-9422(90)80164-C.

Bahorun, T.; Neergheen, S.V. and Aruoma, I.O. (2005). Phytochemical constituents of Cassia fistula. African J. Biotech., 4:1530-1540. doi: 10.4314/ajfand.v4i13.71772.

Bennett, A. (1975). Pharmacology of colonic muscle. Gut, 16:307-311 doi: 10.1136 /gut.16.4.307

Berlyn, G.P. and Miksche, J.P. (1976). Botanical microtechnique and cytochemistry. The Iowa State University Press, Ames, Iowa.

Bhakta, T.; Banerjee, S.; Mandal, S.C., Maity, T.K.; Saha, B.P. and Pal, M. (2001) Hepatoprotective activity of Cassia fistula leaf extract. Phytomedicine, 8:220-224. doi.org/10.1078/0944-7113-00029.

Bruneton, J. (1995). Pharmacology, phytochemistry, medicinal plants. Lavoiser publishing, Paris, pp:349-354.

Chaudhuri, K. and Chawla, H.M. (1987). Anthraquinones and terpenoids from Cassia javanica leaves. J. Nat. Prod., 50:1183-1189. doi: $10.1021 / \mathrm{np} 50054 \mathrm{a} 035$.

Chopra, R.N.; Nayar, S.L. and Chopra, I.C. (1992). Glossary of Indian medicinal plants. Publication and Information Directorate, CSIR, New Delhi, pp. 54.

Dalziel, J.M. (1948). Useful plants of west tropical Africa. Crown Agents for Oversees Governments, London, pp:178-180.

De Witte, P. and Lemli, L. (1990). The metabolism of anthranoid laxatives. Hepatogastroenterology, 37:601-605. PMID: 2289777

Dhanani, T.; Singh, R.; Reddy, N. and Kumar, S. (2017). Comparison on extraction yield of sennoside A and sennoside B from senna (Cassia angustifolia) using conventional and non conventional extraction techniques and their quantification using a validated HPLC-PDA detection method. Nat. Prod. Res., 31:1097-1101.doi: 10.1080/ 14786419.2016 .1258562
Elujoba, A.A.; Ajulo, O.O. and Iweibo G.O. (1989). Chemical and biological analyses of Nigerian Cassia species for laxative activity. J. Pharm. and Biomed. Anal., 7: 1453-1457. PMID: 2490529

Hannebelle, T.; Weniger, B.; Joseph, H.; Sahpaj, S. and Bailleul, F. (2009). Senna alata. Fitoterapia, 80:385-393. doi.org/10.1016/j.fitote.2009.05. 008

Irwin, H.S. and Barneby. R.C. (1982). The American Cassiinae. Memoirs of the New York Botanical Garden 35:1-918.

Irwin, H.S. and Turner, B.L. (1960). Chromosomal relationships and taxonomic considerations in the genus Cassia. American J. Bot., 47:309-318. doi.org/10.1002/j.1537-2197.1960.tb07130.x

Iyengar, M.A.; Pendse, G.S. and Narayana, N. (1966). Bioassay of Cassia fistula L. (Aragvadha). Planta Med., 14:288-301. doi: 10.1055/s-00281100056

Johansen, D.A. (1940). Plant Microtechnique Mc Graw Hill Book Co.Ltd, New York, pp:182.

Khan, S.; Mirza, K.J.; Al-Qurainy, F. and Abdin, M.Z. (2011). Authentication of medicinal plant Senna aunguistifolia by RAPD profiling. Saudi J. Biol. Sci., 18:287-292. doi: 10.1016/j.sjbs.2011.03.001

Kiran, U.; Khan, S.; Mirza, K.J.; Ram. M. and Abdin, M.Z. (2010). SCAR markers : A potential tool for authentication of herbal drugs. Fitoterapia, 81:969-976. doi.org/10.1016/j.fitote.2010.08.002

Kojima, T.; Kishi, M.; Sekita, S. and Satake, M. (2001). Origin of sennosides in health teas including Malva leaves. Shokuhin Eiseigaku Zasshi, 42:202-205.

Kumar, A.; Tripathi, V. and Pushpgandan, P. (2007). Random amplified polymorphic DNA as marker for generic variation and indentification of Senna surattensis Burn, f. and Senna sulfurea DC. Ex Collad. Current Sci., 93:1146-1150.

Lohar, D.R.; Chawan, D.D. and Garg, S.P. (1975). Phytochemical studies on Cassia species of Indian arid zone. Current Sci., 44:67.

Meena, K.L. and Yadav, B.L. (2009). Senna uniflora (mill.) Irwin \& Barneby (Caesalpiniaceae) A new record for Rajasthan. Nat. Prod. Radiance, 8:525-527.

Mondal, A.K. and Mandal, S. (1997). A contribuition to the medicinal plants of Burdwan District, West Bengal. Environment and Ecology, 15:166-174.

Moreau, J.P.; Moreau, S. and Skinner, S. (1985). Comparative physiological disposition of some anthraquinone glycosides and aglycones. Biopharm. Drug Disp., 6:325-334. doi.org/10.1002/bdd.25100 60307 .

Morinaga, O.; Tanaka, H. and Shoyama, Y. (2000). Production of monoclonal antibody against a major purgative component sennoside A, its characterization and ELISA. Analyst, 125:1109-1113. doi.org/ 10.1039/B000988L

Moringa, O.; Uto, T.; Sakamoto S; Putalun, W.; Lhieochaiphant S.;Tanaka, H. and Shoyama, Y. (2009). Development of eastern blotting technique for sennoside $A$ and sennoside $B$ using anti-sennoside $A$ and antisennoside B monoclonal antibodies. Phytochem. Anal., 20:154158 .

Mukherjee, K.S.; Bhattacharjee, P.; Mukherjee, R.K. and Ghosh, P.K. (1987). Anew anthraquinone pigment from Cassia mimosoides Linn. J. Indian Chem. Soc., 64:130.

Mukhopadhyay, M.J.; Saha, A.; Dutta, A.; De, B. and Mukharjee, A. (1998). Genotoxicity of sennosides on the bone marrow cells of mice. Food and Chem. Toxicol., 36:937-940. doi.org/10.1016/S02786915(98)00049-0. 
Nadkarni, A.K. (1976). Indian Materia Medica, Popular Prakashan, Bombay.

Pandya, H.; Kachwala, Y.; Sawant, L. and Pandita, N. (2010). Pharmacognostical screening of seeds of Cassia absus. Pharmacog. J., 2:419-426. doi.org/10.1016/S0975-3575(10)80025-2

Pari, L. and Latha, M. (2002). Effect of Cassia auriculata flowers on blood sugar levels, serum and tissue lipids in streptozotocin diabetic rats. Singapore Med. J., 43:617-621. PMID: 12693765

Pendse, G.S. ; Dange, P.S. and Surange, S.R. (1973). Proceedings of first workshop. All India Coordinated Improvement Project on Medicinal and Aromatic Plants, pp:67.

Putalun, W.; Morinaga, O.; Tanaka, H. and Shoyama, Y. (2004). Development of a one-step immunochrmatographic strip test for the detection of sennosides A and B. Phytochem. Anal., 15:112-116. doi.org/10.1002/ pca. 752

Rai, K.N.; Kaushalendra, K. and Singh, J. (1997). A new anthraquinone glycoside from the heartwood of Cassia auriculata Linn. Asian J. Chem., 9:877-878.

Rastogi, R.P. and Mehrotra, B.N. (1995). Compendium of Indian Medicinal Plants, Vol. VI, Publication and Information Directorate, CSIR, New Delhi, pp:155-163.

Rejiya, C.S.; Cibin, T.R. and Abraham, A. (2009). Leaves of Cassia tora as a novel cancer therapeutic - An in vitro study. Toxicol. in vitro, 23: 1034-1038. doi: 10.1016/j.tiv.2009.06.010

Sakulpanich, A. and Gritsanapan, W. (2009). Determination of anthraquinone glycoside content in Cassia fistula leaf extracts for alternative source of laxative drug. Int. J Biomed. Pharm Sci., 3:42-45.

Saraf, S.; Dixit, V.K.; Tripathi, S.C. and Patnaik, G.K.(1994). Antihepatotoxic activity of Cassia occidentalis. Int. J. Pharmacog., 32:178-183. doi.org/10.3109/13880209409082990
Sharma, R.A.; Singh, D. and Yadav, A. (2012). Phytochemical evaluation and quantification of primary metabolites of Cassia puumila Lamk. Nat. Sci., 10:25-28.

Sihanat, A.; Rungsihirunrat, K.; Palanuvej, C. and Ruangrungsi, N. (2016). Characterization and number of trichome of leaves from selected Cassia spp. in Thailand. Bull. Health Sci. Technol., 14:10-20.

Singh, J. and Singh, J. (1988). Isolation and characterization of two new anthraquinones from the stem bark of $C$. javanica Linn. Indian J. Chem., Sec. B., 27B:858-859.

Singh, R.; Singh, R. and Singh, J. (1999). Two new O- $\beta$-D-glycosides from the stem bark of $C$. javanica Linn. Indian J. Chem., Sec. B, 38B, 521524.

Singh, V. (2001). Monograph on Indian subtribe Cassiinae (Caesalpiniaceae), Scientific Publishers, Jodhpur.

Srebotnik, E. and Messener, K. (1994). A simple method that uses differential staining and light microscopy to assess the selectivity of wood delignification by white rot fungi. Appl. Environ. Microbio., 60:1383-1386. PMID: 16349245

Stoll,A.; Becker, B. and Kussmaul, W. (1949). Die Isolierung der Anthraglykoside aus Sennadrogen. 3. Mitteilung über Anthraglykoside. Helvetica Chimica Acta, 32:1892-1903. doi: 10.1002/hlca.19490320613

The Wealth of India (1992). A dictionary of India raw materials and industrial product-raw materials. Revised Series Vol. 3 (Ca-Ci), Publication and Information Directorate, CSIR, New Delhi, pp:733-751.

Thomson, R.H. (1971). Naturally occurring quinines ( $2^{\text {nd }}$ Edn). Academic Press, London, 367:402-403.

Tiwari, R.D. and Singh, J. (1979). Anthraquinone rhamnosides from Cassia javanica root bark. Phytochemistry, 18: 906. doi: 10.1016/00319422(79)80051-5

Uthaya Kumar, U.S.; Jothy, S.L.; Gothai, S.; Dharmaraj, S.; Chen Y. and Sasidharan, S. (2014). Standardization and Quality Evaluation of Cassia surattensis seed extract. Res. J. Pharma. Biol. Chem. Sci., 5: 355-363. 